Contract No. and Disclaimer:

This manuscript has been authored by Savannah River Nuclear Solutions, LLC under Contract No. DE-AC09-08SR22470 with the U.S. Department of Energy. The United States Government retains and the publisher, by accepting this article for publication, acknowledges that the United States Government retains a non-exclusive, paid-up, irrevocable, worldwide license to publish or reproduce the published form of this work, or allow others to do so, for United States Government purposes. 


\title{
AUTHORIZING THE DOT SPECIFICATION 6M PACKAGING FOR CONTINUED USE AT THE SAVANNAH RIVER SITE
}

\author{
Robert W. Watkins, Bradley M. Loftin, and Don S. Hoang \\ Savannah River National Laboratory \\ Aiken, SC 29808
}

\begin{abstract}
The U.S. Department of Transportation (DOT) Specification 6M packaging was in extensive use for more than 40 years for in-commerce shipments of Type B quantities of fissile and radioactive material (RAM) across the USA, among the Department of Energy (DOE) laboratories, and between facilities in the DOE production complex.
\end{abstract}

In January 2004, the DOT Research and Special Programs Administration (RSPA) Agency issued a final rule in the Federal Register to amend requirements in the Hazardous Materials Regulations (HMR) pertaining to the transportation of radioactive materials. The final rule became effective on October 1, 2004. One of those changes discontinued the use of the DOT specification $6 \mathrm{M}$, along with other DOT specification packagings, on October 1, 2008. A main driver for the change was due to the fact that $6 \mathrm{M}$ specification packagings were not supported by a Safety Analysis Report for Packagings (SARP) that was compliant with Title 10 of the Code of Federal Regulations (CF R) Part 71 (10 CFR 71). The regulatory rules for the discontinued use have been edited in Title 49 of the Code of Federal Regulations (CFR) Parts 100 - 185, 2004 Edition and thereafter. Prior to October 1, 2008, the use of the $6 \mathrm{M}$ within the boundaries of the Savannah River Site (SRS), called an onsite transfer, was governed by an onsite transportation document that referenced 49 CFR Parts 100 - 185. SRS had to develop an Onsite Safety Assessment (OSA) which was independent of 49 CFR in order to justify the continued use of the DOT Specification $6 \mathrm{M}$ for the transfer of radioactive material (RAM) at the SRS after October 1, 2008. This paper will discuss the methodology for and difficulties associated with authorizing the DOT Specification 6M Packaging for continued use at the Savannah River Site.

\section{Introduction}

The applicable governing documents for onsite transfers at the Savannah River Site (SRS) are Savannah River Nuclear Solutions (SRNS) Transportation Safety Manual $19 \mathrm{Q}$ and DOE
Order 460.1B. In turn, these documents require that Type B or Type A fissile packagings meet the requirements of 10 CFR 71 or are compliant with the SRNS Transportation Safety Manual $19 Q$ to ensure adequate safety to the public, SRS workers, and the environment.

Since the 6M was a DOT Specification Packaging, the packaging did not have the Safety Analysis Report for Packaging (SARP) like other NRC or DOE certified Type B or Type A fissile packagings. In the Fall of 1983 a DOE Specification-6M Task Force prepared and organized safety documentation for the $6 \mathrm{M}$ packaging. The result of the Task Force's efforts was the Sandia report, SAND88-3005, A Review of the Safety Features of 6M Packagings for DOE Programs, which has been treated in similar fashion to a formal SARP for the $6 \mathrm{M}$ to support DOE shipping programs. The Sandia report also served as the basis of Type B packaging performance for the SRS OSA since this report documents that the $6 \mathrm{M}$ packaging met the performance requirements for Type B packaging at the time the Sandia report was issued. It should be noted that the focus of the Sandia report was to support in-commerce shipments. In-commerce shipments have the potential to expose the package to conditions that are much more stringent than the conditions encountered during an onsite transfer. The risk of an onsite accident or event is significantly mitigated by SRS safety precautions including the Integrated Safety Management System (ISMS) and the ALARA (As Low As Reasonably Achievable) radiation program. Therefore, there are some recommendations and aspects of the Sandia report that are not applied to the OSA.

\section{Packaging Description}

The original 6M packaging was Dow Chemical Corporation's Model 1518, a 38-L (10-gal) sized container, approved by the U.S. Atomic Energy Commission (now DOE) in March 1967 and issued DOT Special Permit 5000 the following month. The DOT 6M was issued in December 1968 to cover a variety of similar containers ranging in capacity from $38 \mathrm{~L}$ to $417 \mathrm{~L}$ (10 gal - 
110 gal). The $6 \mathrm{M}$ packaging was authorized by the DOT regulations for shipment of Type B and fissile quantities of radioactive materials until October 1, 2008 (49 CFR 173, Subpart I, 2004 Edition and after).

The 6M was a DOT Specification, licenseexempt, lightweight, economical Type B packaging that was easily fabricated from common materials. The $6 \mathrm{M}$ was in extensive service beginning in 1967, especially in the DOE complex, with many 6M packagings still available; mostly in 30-gallon and 55-gallon sizes.

Based upon 40-plus years of actual transportation history, the $6 \mathrm{M}$ has been demonstrated to be a safe and reliable package. Although they have been exposed to incidents of varying severity, there has never been a known release of radioactive contents from a $6 \mathrm{M}$ package due to an accident or due to package deterioration. More history about $6 \mathrm{M}$ packaging can be found in the Sandia report, SAND883005.

The $6 \mathrm{M}$ packaging consists of the outer drum (10 gallon - 110 gallon carbon steel or stainless steel drum), fiberboard insulation, and an inner vessel called the DOT specification 2R. General design requirements for the $6 \mathrm{M}$ packaging are found in 49 CFR 178.354, "Specification 6M; Metal Packaging," and for the DOT-2R inner vessel in 49 CFR 178.360, "Specification 2R; Inside Containment Vessel." (both 2003 Edition or before). The 'built-in' drawings for 6M packaging are listed in the Sandia report.

It should be noted that the regulatory specification requirements for DOT 6M 2R (1980s Editions) are 49 CFR 178.104 (6M) and 49 CFR 178.34 (2R) in the Sandia report.

\section{Onsite Authorization}

The 6M shipping container is used by several SRS facilities to transfer product and samples across the site. Prior to October 1, 2008, the use of the $6 \mathrm{M}$ at the SRS for onsite transfers was governed by an onsite transportation document that referenced 49 CFR Parts 100 - 185. In order to avoid a shut down of material transferred in a 6M after October 1, 2008 an Onsite Safety Assessment (OSA) had to be developed which was independent of 49 CFR in order to justify the continued use of the DOT Specification 6M for the transfer of radioactive material (RAM) at
SRS. SRS OSA document was required to show compliance with the SRNS Transportation Safety Manual, 19Q, in order to ensure adequate safety to the public, SRS workers, and the environment.

The basic challenge for developing a 6M OSA was that the $6 \mathrm{M}$ specification packaging was not supported by a Safety Analysis Report for Packagings (SARP) that was compliant with 10CFR71. As previously mentioned, the Sandia report was the closest document that resembled a SARP for the 6M, and it had been treated in similar fashion to a formal SARP for the $6 \mathrm{M}$ to support DOE shipping programs. The Sandia report served as the basis of Type B packaging performance for the OSA. This report documents that the $6 \mathrm{M}$ packaging met the 10 CFR 71 performance requirements for Type $\mathrm{B}$ packaging at the time the Sandia report was issued.

The OSA for the DOT Specification 6M Packaging addressed the following areas in order to justify continued use at SRS: Content, Structural, Thermal, Containment, Shielding, Criticality, Operations, Maintenance, and Quality Assurance.

The 6M OSA only focused on contents necessary to support SRS missions after October 1, 2008 rather than addressing the entire $6 \mathrm{M}$ content specified in 49 CFR 173.417, Table 5. Therefore the OSA evaluated uranium-235 (metal and oxide), plutonium-239 (metal and oxide), and some limited uranium-233 oxide. Also, the OSA restricted the transfer of fissile contents to 30 -gallon or 55-gallon $6 \mathrm{M}$ drums only.

The Sandia report states, via analyses and tests, that the $6 \mathrm{M}$ packaging complies with 10 CFR 71.71 requirements for Normal Conditions of Transport (NCT) as well as the 10 CFR 71.73 requirements for the Hypothetical Accident Conditions (HAC) test sequence (30foot free drop, puncture, thermal, immersion).

Structural integrity of a package under NCT and HAC is paramount. The Sandia report showed via analyses and testing that the $6 \mathrm{M}$ drum met all of the 10 CFR 71 requirements for NCT and HAC relating to structural integrity. This included the drum body and closure, the fiberboard insulation material, and the $2 \mathrm{R}$ containment vessel. However, other more recent 
studies have shown some vulnerability of singlebolt, clamp-ring drum lids in drop tests. These tests produced similar structural loadings on the packaging as those experienced in the Sandia testing. Although the drum body may be more vulnerable during the 30 -foot drop tests, these new tests do not alter the Sandia report conclusion with regard to the structural integrity or containment capability of the $2 \mathrm{R}$ vessel. The OSA reasons that there are no scenarios where the package would be vulnerable to drop heights approaching 30-feet, and for the use at the SRS, it is assumed that the $6 \mathrm{M}$ drum and closure remain in tact after an accident. These more recent tests were designed to replicate specific orientations expected to challenge the drum lid, and the combination of these accident orientations in severe accidents combined with a fire is judged to be improbable $(<1 \%)$ within the boundaries of the SRS. This reasoning allows the rest of the Sandia report to be applied to the OSA.

The Sandia report details by analyses and tests that the $6 \mathrm{M}$ packaging maintains thermal performance following the NCT and HAC thermal tests. The maximum temperature reached at the inner liner of the 10 -gallon $6 \mathrm{M}$ container (payload region) was $117^{\circ} \mathrm{C}\left(243^{\circ} \mathrm{F}\right)$. That temperature is less than $149^{\circ} \mathrm{C}\left(300^{\circ} \mathrm{F}\right)$ which is the acceptable level required for gasket material and/or non-hardening luting compound compatibility for the $2 \mathrm{R}$ vessel. The $6 \mathrm{M}$ package was shown to maintain thermal performance during and following the HAC test sequence using both analyses and tests. The maximum temperature reached at the inner liner of the 10 -gallon $6 \mathrm{M}$ container was $120.3^{\circ} \mathrm{C}$ $\left(248^{\circ} \mathrm{F}\right)$.

The principal containment boundary for the $6 \mathrm{M}$ packaging is the $2 \mathrm{R}$ vessel with secondary containment provided, in most cases, by sealed food pack cans. This combination is shown in the Sandia report to provide containment meeting the NCT release limit of $10^{-6} \mathrm{~A}_{2}$ per hour. Tests and calculations described in the Sandia report demonstrate the ability of the $6 \mathrm{M}$ to meet the containment requirement of releasing no more than one $A_{2}$ per week after the HAC accident sequence. These conclusions remain true even though the more recent studies have shown some vulnerability of single-bolt, clampring drum lid in drop testing.
For shielding the OSA relies on the controls implemented by the SRS Radiological Control program. The regulations within 49 CFR for the $6 \mathrm{M}$ allowed for inserts to be placed into the $2 \mathrm{R}$ vessel that provided radiation shielding. The $6 \mathrm{M}$ OSA at SRS does not restrict the use of inserts and allows the user to implement any methods for shielding that comply with the applicable SRS procedures.

The contents authorized by the $6 \mathrm{M}$ OSA were evaluated by a Nuclear Criticality Safety Evaluation (NCSE) and shown to be subcritical during NCT and after the HAC sequence. This NCSE evaluates a variety of contents and fissile loading for the $6 \mathrm{M}$ package. The limits generated by this NCSE are included in the $6 \mathrm{M}$ OSA as content limits.

No changes to the $6 \mathrm{M}$ operation or maintenance as previously outlined in 49CFR or the Sandia report were needed for continued use at SRS. The OSA uses the information found in 49 CFR as well as in the Sandia report and documents the actions needed for SRS facilities to operate and maintain the packagings.

Quality Assurance for the $6 \mathrm{M}$ is provided by adherence to the SRS Quality Assurance Management Plan which is based on requirements founding DOE Order 414.1C. The SRS Quality Assurance Manual describes the procedures to be followed in the implementation of the QA Plan. Further, the QA Program developed from the requirements in the SRS Quality Assurance manual complies with DOE Order 460.1B, 10 CFR 830.120, Subpart $\mathrm{H}$ of 10 CFR 71, and NQA-1. Site Quality Assurance, Quality Control, inspection, maintenance, operation (loading, unloading), transportation, repair, i.e., manual / procedures already exist and are in place to maintain specific packaging and transportation activities of the existing 6M packagings.

\section{Conclusion}

The OSA for the DOT Specification 6M Packaging was approved for use at SRS facilities on September 22, 2008, just prior to the $6 \mathrm{M}$ expiration date of October 1, 2008. The initial OSA document authorized only limited content from Table 5 in 49 CFR 173.417 which enabled SRS facilities to have procedures in place prior to October 1, 2008 so that onsite transfers of RAM in 6M packages were not impacted. Additional revisions to the 6M OSA since 
October 2008 have added more content to support SRS missions. Because of the OSA, the $6 \mathrm{M}$ shipping container remains in use by SRS facilities to transfer product and samples across the site in a safe and efficient manor. 